\title{
Diferentes olhares, outras perspectivas: solidariedade e trabalho doméstico para mulheres negras durante a escravidão e no pós-abolição
}

XAVIER, Giovana; FARIAS, Juliana Barreto; GOMES, Flávio (Orgs.). Mulheres negras no Brasil escravista e do pós-emancipação. São Paulo: Selo Negro Edições, 2012.

Bruna Cristina Jaquetto Pereira*

M ulheres negras no Brasil escravista e do pós-emancipação, publicado em 2012 pela Selo Negro Edições, tem organização de Giovana Xavier, Juliana Barreto Farias e Flávio Gomes, historiadores/as que se dedicam ao estudo da diáspora negra, da escravidão e do período pós-abolição. Nos dezenove capítulos da obra, vinte autoras/es apresentam suas pesquisas sobre o cotidiano de pessoas escravizadas, libertas e de suas/seus descendentes durante os séculos XVIII, XIX e início do século XX. O livro reforça uma tendência observada na historiografia brasileira desde a década de 1980. Inova, contudo, por sua proposta de tratar da vida das mulheres, ao que se soma, de forma enriquecedora, a diversidade temporal, espacial e temática das abordagens. Sua unidade articula-se por um interesse comum, que opera como espinha dorsal.

Nas páginas de Mulheres negras no Brasil escravista e do pós-emancipação, ganham vida mulheres negras escravizadas e forras, africanas e crioulas (nascidas no Brasil), que, emergindo de fontes documentais, de fotografias ou da literatura, transitam por domicílios próprios ou alheios, no campo, nas ruas, em minas, irmandades, confrarias, associações e na capoeira, em todas as regiões do país. Suas existências desfolham-se a partir de identidades e funções tais como as de mãe, dona de escravas/os, ama de leite, criada, quitandeira, locatária, amante, prostituta, esposa/ companheira, comadre e professora - ou seja, para além da fixação na limitadora díade senhor/a-escravo/a.

A obra presta-se à observação de recorrências que convidam à análise sociológica. As experiências e ações que descreve calcam-se no status compartilhado de diferentes mulheres negras frente às hierarquias sociais de gênero e raça, que resultam em desafios comuns e que originam, por vezes, pontos de vista e projetos similares ${ }^{1}$. Considerá-las a partir desta perspectiva contribui para a pluralização

\footnotetext{
* Doutoranda em sociologia pela Universidade de Brasília. <brunacjpereira@ gmail.com>.

1. Ver, a esse respeito, Patricia Hill Collins (2000).
} 
dos estudos sociológicos e "enegrecer" os estudos feministas e de gênero (Carneiro, 2003).

Em primeiro lugar, destacam-se certos padrões de solidariedade entre mulheres negras. A instabilidade das relações sociais, o frequente esfacelamento das famílias pela venda das/os cativas/os e a importância estratégica das alianças para a sobrevivência e resistência no contexto escravista ensejaram vínculos que substituíam ou se somavam aos laços conjugais e de consanguinidade. Estudos a partir de testamentos e de documentos de grupos religiosos expõem algumas características dessas redes de relacionamento.

A obtenção da manumissão e até o enriquecimento pela mineração, comércio ou prostituição não foram incomuns nas Minas Gerais do século XVII, desencadeando mesmo medidas de confisco de riquezas por parte da coroa portuguesa. Antes disso, Bárbara de Oliveira (capítulo 1, de Eduardo França Paiva) tratou de constituir uma das maiores fortunas entre libertas/os em Minas Gerais, através da prostituição própria e de suas escravas. A crioula dispunha de 23 cativas/os que compunham núcleos familiares e viviam em conjunto, provavelmente na mesma casa habitada pela proprietária.

A análise do testamento de Bárbara e dos registros sobre os legados de outras mulheres descreve um interessante sistema de transmissão de bens sociais e materiais. No documento, ela alforriava ou coarctava quase todas/os suas/seus escravas/os e suas/seus filhas/os, além de distribuir joias, móveis, roupas, dinheiro e imóveis entre elas/eles e também com uma filha, que permanecera escravizada na Bahia. O interesse pelo bem-estar de algumas de suas protegidas estendia-se para além da melhoria das condições materiais, e o acesso à herança estava condicionado, para essas, ao casamento, com o intento explícito de incentivá-las a viver com "honra".

Por sua vez, Maria da Saúde, Teresa Maria de Jesus, Ronalda Maria do Sacramento e Maria de Assunção Cintra (capítulo 2, de Adriana Dantas Reis), que viveram na Bahia do início do século XIX, transmitiram bens a mulheres que já não constituíam mais sua propriedade. Quanto a Maria da Saúde, a documentação expressa seu desejo de deixar valores e patrimônios para escravas e libertas que pertenciam ou haviam pertencido a outras/os proprietárias/os. Teresa, Ronalda e Maria do Sacramento determinavam ainda a compra de uma casa para usufruto de algumas de suas escravas libertas e suas famílias. Evidenciam-se assim laços de solidariedade que duraram para além da convivência cotidiana e da relação proprietárias-propriedades, bem como preocupações quanto à conservação e ao abrigo de famílias. 
A preocupação com a manutenção do núcleo familiar emerge também na história de Rosa O'Freire (capítulo 9, de Sandra Lauderdale Graham), africana liberta que, em 1863, registrava a concessão de liberdade às suas escravas Leocádia e Guilhermina após sua morte, assim como também aos filhos de Leocádia - prática então incomum. Por fim, do registro do testamento de Sebastiana Inácia (capítulo 19, de Marcelo Paixão e Flavio Gomes), de 1826, Rio de Janeiro, delineia-se a importância relativa aos laços conjugais frente a outros vínculos sociais, uma vez que ela deixava apenas parte dos bens para o marido. Além de libertar escravas/os e suas/seus fiIhas/os, Sebastiana destinava-Ihes boa parte de suas propriedades.

As/Os autoras/es atribuem o legado de herança a cativas e libertas à gratidão pelo auxílio prestado na aquisição de bens e, em alguns casos, também de posição social de destaque relativo. Pode-se ainda especular que os laços afetivos e uma similaridade de origem das testadoras com a condição das herdeiras tenham impactado as escolhas quanto ao repasse de valores. De toda forma, o certo é que as decisões das proprietárias culminaram no que Adriana Reis identifica como "uma reprodução de mobilidade ascendente entre mulheres" (p. 33). Ou seja, a alforria e a ascensão na hierarquia social por parte de uma mulher negra refletiam-se na vida de outras mulheres negras, de onde se amplificavam para suas famílias ou redes sociais.

Na obra, também a religião emerge como fonte de solidariedade entre negras/os nascidas/os livres, libertas/os e escravas/os. Para mulheres como Luzia, preta forra, ou como as escravas Maria Canga e Antônia Luzia (capítulo 3, de Luciana Figueiredo), que viveram em Minas Gerais, a prática do calundu foi em alguns momentos capaz de arrefecer "o conflito sob o cotidiano da escravidão" e também de estreitar "a solidariedade e empurrar cativos e forros para o rompimento" (p. 45). Contudo, a adesão às práticas religiosas de matriz africana não estava isenta de riscos, pois as histórias dessas mulheres foram resgatadas dos documentos de sua condenação pelos tribunais da Inquisição.

São ainda retratadas no livro relações de cooperação estabelecidas por meio das irmandades de pretas/os. No final do século XVIII e início do século XIX, na capitania de Goiás, a Irmandade de Nossa Senhora do Rosário dos Pretos, localizada em Natividade, ocupou o posto de maior Igreja Católica do Brasil Central (capítulo 4, de Mary Karasch). Encontradas em todo o território nacional, essas organizações funcionavam a partir de doações das/os associadas/os e providenciavam, em contrapartida, assistência a idosas/os, funerais, esmolas, cuidado a doentes, cartas de alforria e orações pela alma das/os mortas/os. A participação de mulheres negras - crioulas, africanas, livres, forras e escravizadas - foi fundamental para a existência das irmandades, tanto em virtude de suas contribuições volumosas como pela participação em posições de liderança nos conselhos e grupos dirigentes. Em Nati- 
vidade, elas eram rainhas, juízas e irmãs de mesa - postos vetados às mulheres em irmandades de brancas/os.

A história de Teresa de Jesus e Sousa, habitante do Recife no início do século XIX (capítulo 7, de Valéria Gomes da Costa), ilustra outro papel da religião para a construção das redes sociais de mulheres negras. Africana liberta, Teresa, que não teve filhas/os, "constituiu uma família ampliada a partir das relações de compadrio, agregando vários afilhados tanto africanos quanto crioulos" (p. 102), escravas/os e libertas/os, em sua maioria mulheres. Quando cativas, as afilhadas contavam possivelmente com o auxílio de Teresa e de seu marido para a obtenção da manumissão e de meios de sobrevivência; quando libertas, beneficiavam-se da doação de valores e de maior trânsito por espaços religiosos e sociais.

Nota-se, portanto, que a acumulação e o status propiciados pelas atividades comerciais de Teresa não se restringiram a uma ascensão social de cunho individual(ista) ou restrita ao seu círculo de consanguinidade. Antes, pela forma como se estenderam a toda uma rede de pessoas, pode-se mesmo falar em "mecanismos elaborados por escravos e libertos em seus projetos coletivos de autonomia", ou em relações de cunho clientelista nas quais os favores não operavam apenas de cima para baixo, mas também a partir de "promessas recíprocas de serviços, obediência, deferência e lealdade" (p. 103).

Uma segunda recorrência temática presente na obra merece ainda menção. Em consonância com a concentração da mão de obra feminina negra na prestação de trabalho doméstico, três dos capítulos dedicam-se às relações sociais e condições laborais de amas e criadas. Nas atividades de amas e criadas, sobressaem-se lógicas distintas daquelas que povoam o entendimento sociológico clássico sobre trabalho. Sobretudo, destacam-se a convivência subalterna com as/os proprietárias/os e suas famílias e a expressão de afeto como habilidade e imperativo, especialmente no cuidado de crianças. Se a crença no favorecimento das/os escravas/os domésticas/os levou pesquisadoras/os a propagar que as relações escravistas foram mais amenas

2. Ver Sandra Graham (1992) nesse âmbito do que na lavoura², por exemplo, a obra desvela a adoção estratégica de posturas que vão da condescendência a expressões abertas de hostilidade às condições opressivas, indicativas das acirradas tensões.

A história da Joaquina (capítulo 12, Sandra Koutsoukos), transcorrida em 1803 no Rio de Janeiro, ilustra como as amas por vezes mobilizaram externalizações de afetos para garantir melhores condições de sobrevivência. Joaquina foi para cuidar das filhas de um casal, em virtude da maneira carinhosa com que as tratava, e deveria ser libertada após três anos de serviços prestados. Passado algum tempo do acordo, ela passou a comportar-se, segundo a família proprietária, de maneira desobedien- 
te e petulante, até mesmo retribuindo a agressão física que a proprietária certa vez Ihe desferiu. A inicial atitude subserviente transformou-se em contestação das humilhações a que se via submetida tão logo Joaquina percebeu que sua liberdade estava assegurada.

Ambrosina (capítulo 13, de Maria Helena Machado), por sua vez, foi deslocada contra sua vontade de Mogi Mirim (SP) - onde residia seu proprietário -, para Taubaté (SP) com o objetivo de amamentar Benedito, filho recém-nascido de um juiz. A amamentação e o cuidado do bebê proprietário, desempenhadas de má vontade, cumpriam-se às custas do afastamento de Ambrosina de seu próprio filho, também chamado Benedito. Frágil e inconsciente, o Benedito branco já Ihe dominava o corpo e a ele impunha suas precisões e vontades, enquanto Ambrosina deveria suportar o choro do seu Benedito, não menos delicado e necessitado, sem que pudesse acalentá-lo.

Os autos do processo criminal que relata a história, de 1886, indicam a escalada dos conflitos entre senhoras/es e a cativa antes do desfecho dramático: a morte por sufocamento da criança branca. Cansada, insone e sem leite, Ambrosina ouviu o seu pequeno senhor chorar, tendo sido ainda repreendida a mando da senhora. Irritada, introduziu uma boneca na boca do bebê, matando-o. Com a criança, morre também o estereótipo da ama fiel e amorosamente devotada à criança branca. Afinal, conquanto muitas amas por certo afeiçoaram-se às crianças a que se dedicaram, tais vínculos se forjaram às custas da proximidade com suas/seus próprias/os filhas/os ou, de qualquer forma, independentemente de sua vontade. Ainda que trágica, a história é representativa do grau e da natureza da violência a que estavam submetidas as amas, resultando em intensos conflitos internos e externos que, no limite, culminavam em eventos nefastos.

Também o desempenho dos afazeres domésticos apresentava tensões latentes ou abertas, ancoradas em relações de autoridade, dependência e hierarquia, mesmo quando envolviam a concessão de privilégios (capítulo 16, de Flávia Fernandes de Souza). O trabalho das criadas na Corte Imperial esteve dotado lógicas de dominação em que os "ganhos' gerados pela proximidade e pela familiaridade" (p. 255) inserem-se em uma ideologia de domínio paternalista e controle social que foi central para o estabelecimento e a manutenção das relações escravistas. A escravidão doméstica, como sistema social de dominação e exploração, caracterizou-se pela simultaneidade e complementaridade de afetos e violências, e não por sua oposição em uma díade.

As vivências retratadas no livro deslocam o foco de categorias quase sempre tomadas como centrais para todos os grupos sociais (como "família") para outros víncu- 
los, compreendidos não como desviantes ou anômicos, mas a partir de sua natureza própria e de sua relevância sociológica. Permitem, assim, que conceitos como "trabalho" sejam revisados e se tornem mais precisos. Exemplificam ainda relações de dominação extensas e complexas que atingem mulheres, porém que não se esgotam no binarismo homem/mulher. Por fim, explicitam experiências do feminino que não estão calcadas em referências à fragilidade e à centralidade da vivência romântica ou da maternidade.

\section{Referências}

CARNEIRO, Sueli. Mulheres em movimento. Estudos avançados, v. 17, n. 49, p. 117133, 2003.

COLLINS, Patricia Hill. Black feminist thought. New York: Routledge, 2000.

GRAHAM, Sandra Lauderdale. Proteção e obediência. São Paulo: Companhia das Letras, 1992. 